\title{
Особенности метастазирования рака яичника
}

\author{
Р.Н. Мустафинн, , Л.В. Халикова', Э.К. Хуснутдинова \\ ${ }^{1}$ Башкирский государственный медицинский университет, Россия, Республика Башкортостан, Уфа \\ ${ }^{2}$ Институт биохимии и генетики Уфимского федерального исследовательского центра РАН, Россия, Республика \\ Башкортостан, Уфа \\ * Контакты: Мустафин Рустам Наилевич, e-mail: ruji79@mail.ru
}

\section{Аннотация}

В обзорной статье представлены данные о преимущественных механизмах метастатического прогрессирования рака яичника. Отображены морфофункциональные особенности большого сальника, как способствующие распространению раковых клеток, так и оказывающие противоопухолевое воздействие. Соотношение этих двух взаимопротивоположных свойств зависит от клеточного состава, содержания молекул экстрацеллюлярного матрикса и биомеханических свойств большого сальника при канцерогенезе. Млечные пятна являются основным местом имплантации раковых клеток. Они отличаются от лимфатических узлов более простым строением и уникальным клеточным составом (макрофаги, В-клетки, CD4 ${ }^{+}$и CD8 ${ }^{+}$Т-лимфоциты, другие иммунные клетки), который значительно меняется при метастазировании. M2-макрофаги, адипоциты, $\mathrm{CD} 33^{+}$и $\mathrm{CD}^{+} \mathrm{CD} 25^{\mathrm{high}}$ CD127 low T-супрессоры способствуют миграции, инвазии, росту и колонизации раковых клеток. Большинство молекул, синтезируемых в большом сальнике при метастазировании, также стимулируют данный процесс. Исключением являются Е-кадгерин, CXCL10, CXCL11, CXCR3, которые подавляют рост опухолевых очагов. Кроме того, $\mathrm{CD8}^{+} \mathrm{T}$-лимфоциты и M1-макрофаги также оказывают противоопухолевое воздействие. Поскольку рак яичника характеризуется высокой смертностью, главным образом вследствие метастазов, актуальным является вопрос оптимизации методов прогнозирования эффективности лечения болезни в зависимости от клеточного состава и экспрессии специфических молекул в млечных пятнах большого сальника. Данные показатели могут быть применены в клинике с помощью молекулярно-генетических и иммуногистохимических методов. Для определения необходимости оментэктомии при хирургическом лечении рака яичника и прогнозирования исхода целесообразно изучение морфофункциональных свойств большого сальника с определением количества иммунокомпетентных клеток и характера экспрессии ассоциированных с худшим прогнозом генов, кодирующих активин-A, N-кадгерин, CCL23, CD36, CD44, CF-1/M-CSF, FABP4, GRO- $\alpha$, GRO- $\beta$, IL-8, ITGA2, MMP9, TP53, VEGF, VEGFR. Данные молекулы связаны с системами адгезии и ангиогенеза, играющими ключевую роль в метастазировании. Перспективными направлениями в терапии метастатического рака яичника могут быть стимуляция перехода М2- в М1-макрофаги, активация противоопухолевого антиген-специфического ответа $\mathrm{CD8}^{+}$Т-клеток при помощи фагоцитов, адаптивный перенос натуральных киллерных клеток, применение ингибиторов Wnt-путей, CCR1, CD36, FABP4, PAD4, ITGA2.

Ключевые слова: рак яичника, большой сальник, канцероматоз, лимфоциты, метастазы, млечные пятна, генная экспрессия

Дляцитирования:Мустафин Р.Н., Халикова Л.В., Хуснутдинова Э.К. Особенности метастазирования рака яичника. Креативная хирургия и онкология. 2020;10(4):319-329. https://doi.org/10.24060/2076-3093-2020-10-4-319-329

\author{
Мустафин Рустам \\ Наилевич - \\ к.б.н., кафедра \\ медицинской генетики \\ и фундаментальной \\ медицины, \\ orcid.org/0000-0002-4091-382X \\ Халикова Лариса \\ Вячеславовна - \\ кафедра гистологии \\ orcid.org/0000-0003-1266-5774 \\ Хуснутдинова Эльза \\ Камилевна - \\ д.б.н., npoфeccop \\ orcid.org/0000-0003-2987-3334
}




\section{Specific Features of Ovarian Cancer Metastasis}

Rustam N. Mustafin Cand. Sci. (Biol.), Department of Medical Genetics and Fundamental Medicine orcid.org/0000-0002-4091-382X

Larisa V. Khalikova Department of Histology, orcid.org/0000-0003-1266-5774

Elza K. Khusnutdinova Dr. Sci. (Biol.), Professor, orcid.org/0000-0003-2987-3334

\author{
Rustam N. Mustafin 1, ${ }^{1,}$ Larisa V. Khalikova', Elza K. Khusnutdinova ${ }^{2}$ \\ ${ }^{1}$ Bashkir State Medical University, Ufa, Russian Federation \\ ${ }^{2}$ Institute of Biochemistry \& Genetics of Ufa Science Centre of the RAS, Ufa, Russian Federation \\ * Correspondence to: Rustam N. Mustafin, e-mail: ruji79@mail.ru
}

\section{Abstract}

This review presents data on the predominant mechanisms of metastatic progression of ovarian cancer. The morphological and functional features of the greater omentum are shown, both promoting the spread of cancer cells and having an antitumour effect. The ratio of these two mutually opposite properties depends on the cellular composition, the content of extracellular matrix molecules and the biomechanical properties of the greater omentum during carcinogenesis. Milky spots are the main site of cancer cell implantation. They differ from lymph nodes in a simpler structure and a unique cellular composition (macrophages, $\mathrm{B}$ cells, $\mathrm{CD}^{+}$and $\mathrm{CD8}^{+} \mathrm{T}$ lymphocytes, other immune cells) changing significantly during metastasis. M2-macrophages, adipocytes, $\mathrm{CD}_{3}{ }^{+}$and $\mathrm{CD}^{+} \mathrm{CD} 25^{\text {high }} \mathrm{CD} 127^{\text {low }} \mathrm{T}$-suppressors promote migration, invasion, growth and colonization of cancer cells. The majority of the molecules synthesized in the greater omentum during metastasis also stimulate this process. The exceptions are E-cadherin, CXCL10, CXCL11, CXCR3, which inhibit the growth of tumour foci. In addition, $\mathrm{CD8}^{+} \mathrm{T}$ lymphocytes and M1 macrophages also have antitumor effects. Since ovarian cancer is characterized by high mortality, mainly due to metastases, the issue of optimizing methods for predicting the treatment effectiveness depending on the cellular composition and expression of specific molecules in the milky spots of the greater omentum is urgent. These indicators can be applied in clinical practice using molecular genetic and immunohistochemical methods. In order to determine the need for omenectomy in the surgical treatment of ovarian cancer and to predict the outcome, it is advisable to study the morphological and functional properties of the greater omentum and to determine the number of immunocompetent cells and the nature of the expression of genes associated with the worst prognosis, those encoding activin-A, N-cadherin, CCL23, CD36, CD44, CF-1/M-CSF, FABP4, GRO- $\alpha$, GRO- $\beta$, IL-8, ITGA2, MMP9, TP53, VEGF, VEGFR. These molecules are associated with adhesion and angiogenesis systems that play a key role in metastasis. Promising directions in the therapy of metastatic ovarian cancer can be stimulation of the transition of M2- to M1-macrophages, activation of the anti-tumour antigen-specific response of $\mathrm{CD}^{+} \mathrm{T}$ cells using phagocytes, adaptive transfer of natural killer cells, the use of inhibitors of Wnt pathways, CCR1, CD36, FABP4, PAD4, ITGA2.

Keywords: ovarian cancer, greater omentum, carcinomatosis, lymphocytes, metastases, milky spots, gene expression

For citation: Mustafin R.N., Khalikova L.V., Khusnutdinova E.K. Specific Features of Ovarian Cancer Metastasis. Creative Surgery and Oncology. 2020;10(4):319-329. https://doi.org/10.24060/2076-3093-2020-10-4-319-329 


\section{Введение}

Рак яичника (РЯ) является одним из наиболее распространенных онкологических заболеваний женской репродуктивной системы (второе место после рака молочной железы для женщин старше 40 лет) [1]. Данная патология характеризуется высокой смертностью в течение первого года после установления диагноза (22 \%) и самой высокой летальностью среди всех гинекологических злокачественных опухолей. Пятилетняя выживаемость при РЯ составляет менее 30 \% [2]. Ежегодно в мире регистрируется 240000 новых случаев РЯ [1]. Для болезни специфично длительное бессимптомное течение, в связи с чем диагноз устанавливают в основном на III-IV стадиях [3], после обширного распространения опухоли в брюшной полости, что ограничивает эффективность хирургического вмешательства и химиотерапии. Основной причиной смерти от РЯ являются резистентные к терапии метастазы [2].

Более 90 \% случаев РЯ характеризуются эпителиальной гистологией, включая подтипы серозный, муцинозный, эндометриоидный, светлоклеточный, переходный, плоскоклеточный, смешанный, недифференцированный и неклассифицируемый. Среди них серозный эпителиальный РЯ является самым распространенным [4]. Существуют 3 потенциальные области возникновения РЯ: поверхность яичника, фаллопиевы трубы и выстланные мезотелием перитонеальные полости. Туморогенез РЯ развивается по ступенчатому механизму от медленно растущей пограничной опухоли до хорошо дифференцированной карциномы (тип I), или формируется генетически нестабильная быстро метастазирующая высокозлокачественная серозная карцинома (тип II). В отличие от гематогенно метастазирующих опухолей, раковые клетки при РЯ диссеменируются главным образом внутри брюшной полости и только поверхностно инвазивны. Однако быстрорастущие метастазы сдавливают внутренние органы и часто устойчивы к химиотерапии, что является причиной высокой смертности [3]. Большой сальник (БС) является самой частой областью метастазирования РЯ [5]. Диссеминация из первичной опухоли происходит главным образом путем слущивания с поверхности капсулы яичника клеток, которые затем распространяются током циркулирующей перитонеальной жидкости. И, хотя раковые клетки могут прикрепляться к любой внутрибрюшной поверхности, БС является избирательным местом для их фиксации и агрессивного опухолевого роста с последующим рассеиванием по всем частям брюшной полости [6].

БС является областью для метастазирования не только РЯ, но и опухолей других органов брюшной полости. У разных видов животных БС обычно выходит за пределы желудка и состоит из мембранных слоев жировой ткани с агрегатами лейкоцитов, вкрапленных среди адипоцитов. Первичное прикрепление и последующий рост раковых клеток ограничены определенными участками внутри БС - млечными пятнами (МП), состоящими из организованных агрегатов иммунных клеток, которые содержат сложную сеть капилляров с высокой плотностью сосудов, способствующих выживанию РК
[7]. Сходные с МП структуры, известные как FALC (fatassociated lymphoid clusters), обнаружены и в других жировых депозитах: перикардиальном, средостенном и в плевральной полости. Они подобны МП по строению, содержат те же популяции лейкоцитов и выполняют аналогичные функции. Однако МП отличаются наибольшим количеством кластеров клеток на 1 грамм ткани по сравнению с FALC. Вокруг гонад и в подкожном жире очень мало скоплений лейкоцитов, которые бы напоминали МП или FALC [8]. Доказано, что млечные пятна являются основным местом имплантации злокачественных клеток при перитонеальной диссеминации [9]. В эксперименте in vivo было выявлено, что клетки РЯ размещаются и растут преимущественно в МП сальника, а не в отложениях жира в брюшине. Подобным же образом среда, кондиционированная жировой тканью, содержащей МП, вызывает миграцию на 75 \% больше РК по сравнению со средой, лишенной МП [10].

Наличие скрытых метастазов в БС на ранней стадии РЯ стало причиной включения оментэктомии в хирургическое лечение РЯ с целью точного определения стадии и предотвращения прогрессирования болезни. В то же время результаты лабораторных исследований о роли БС и его МП в развитии РЯ противоречивы [11]. С одной стороны, БС способствует прогрессированию опухолевого процесса. С другой стороны, имеются данные о противоопухолевых свойствах БС [9], которые могли бы стать основой таргетной терапии. Кроме того, на ранней стадии РЯ изолированные микрометастазы в БС встречаются редко (в 2-7 \% случаев) и чувствительны к химиотерапии [12]. Сомнительной является также необходимость удаления БС при запущенных случаях РЯ. Так, анализ результатов хирургического лечения 20975 пациентов с инвазивным РЯ показал, что оментэктомия не улучшает выживаемость при IIIA стадии, в связи с чем встает вопрос о целесообразности этой процедуры [13]. Более актуальным и перспективным является подход в изучении морфофункциональных особенностей БС как для прогнозирования исхода РЯ, так и для разработки наиболее эффективных способов таргетной терапии.

\section{Роль молекул экстрацеллюлярного матрикса и клеток большого сальника в метастазировании рака яичника}

БС взрослого человека имеет общую площадь поверхности около $1500 \mathrm{~cm}^{2}$ и состоит из клеток мезотелиального происхождения. Он свисает в виде фартука над органами брюшной полости, контактируя с селезенкой, желудком, поджелудочной железой и толстой кишкой. БС участвует в васкуляризации, ускоренном заживлении и ограничении инфекции в брюшной полости за счет проявления ангиогенной, фибротической, иммунной активностей и содержания стволовых клеток. Однако данные свойства могут способствовать развитию патологических процессов, таких как метастазирование [14]. Млечные пятна БС, являющиеся основным местом для имплантации клеток РЯ при перитонеальной 
диссеминации, представляют собой небольшие структуры без капсулы, которые начинают формироваться у эмбриона человека с 20 -й по 35-ю неделю беременности. Они состоят из макрофагов, лимфоцитов и плазматических клеток, которые доставляются кровеносными и лимфатическими сосудами из кроветворных органов. Механизм образования МП связан с агрегацией большого количества иммуноцитов в периваскулярные области клубочковой сети кровеносных сосудов для обмена жидкости между брюшной полостью, кровотоком и окружающей тканью БС. Сальниковые клубочки лежат непосредственно под прерывистым слоем мезотелия, который содержит поры и устья, обеспечивающие прямое сообщение с брюшной полостью [9]. При метастазировании клетки РЯ взаимодействуют с микроокружением МП, к которым относятся мезотелиоциты, фибробласты, адипоциты, эндотелиоциты, стромальные компоненты [4]. МП в большом сальнике значительно отличаются по строению, клеточному составу и функционированию от обычных лимфоидных органов. Кластеры лейкоцитов в МП поддерживаются ретикулярной сетью стромальных фибробластов и не содержат фолликулярные дендритные клетки. Т-лимфоциты группируются вокруг кровеносных сосудов и в области расположения В-клеток. Выявляются $\mathrm{CD} 4^{+}$и $\mathrm{CD} 8^{+}$ Т-клетки, однако, в отличие от лимфоидных органов, нет четкой зоны их расположения. Значительную часть клеток МП составляют В-лимфоциты. Однако количество $\operatorname{IgM}^{\mathrm{hi}} \operatorname{IgD}^{\text {lo }}$ B1-клеток превышает таковое $\operatorname{IgM}^{\mathrm{lo}} \operatorname{Ig} \mathrm{D}^{\mathrm{hi}}$ В2-клеток, тогда как в обычных лимфоидных органах наблюдается обратная картина [8]. В норме клеточный состав МП следующий: макрофаги - 46,9 \%, Т-лимфоциты $-21,1$ \%, В-лимфоциты $-18,7$ \%, другие иммунные клетки - 13,3 \%. Размеры МП при метастазах в них значительно возрастают. Например, при раке толстой кишки их диаметр увеличивается в среднем до 768 мкм (в норме 293 мкм), а клеточный состав меняется в пользу Т-клеток $(44,7 \%)$ и В-лимфоцитов $(26,8 \%)$ с относительным уменьшением количества макрофагов $(18,3 \%)$ и других иммунных клеток (10,2\%) [15].

БС поддерживает уникальную популяцию $\mathrm{CD}^{+}$peгуляторных клеток, которые экспрессируют хемокиновые рецепторы CCR1 и CCR2 и на высоком уровне синтезируют IL-10 и CD36 (участвует в метаболизме жирных кислот) [16]. Кроме того, для РЯ, в отличие от доброкачественных опухолей яичника, характерен высокий уровень $\mathrm{CD} 4^{+} \mathrm{CD} 25^{\text {high }} \mathrm{CD} 127^{\text {low }} \mathrm{T}$-супрессоров и ассоциированных с ними цитокинов TGF- $\beta 1$ и IL-19R. Уровни этих маркеров коррелируют с метастазами РЯ. Важное значение в регуляции пролиферации, апоптоза и ангиогенеза клеток РЯ играют матриксные металлопротеиназы (ММР), среди которых МMP-2 и ММР-9 денатурируют и расщепляют главным образом коллаген IV типа и желатин. Тканевые ингибиторы матриксных металлопротеиназ (ТIMP) играют ключевую роль в поддержании гомеостаза экстрацеллюлярного матрикса и его ремоделировании при повреждении. Изменения экспрессии ММР-2 и ТIMР-2 при РЯ тесно связаны с уровнями IL- 10 и TGF- $\beta 1$, секретируемыми
$\mathrm{CD}^{+}$Т-супрессорами [17]. Макрофаги БС способствуют миграции и колонизации клеток РЯ в нем путем продукции хемокиновых лигандов (CCL6 у мыши и CCL23 у человека), взаимодействующих с хемокиновыми рецепторами 1 (CCR1 - chemokine receptor 1), за счет чего активируются пути PI3K и ERK1/2. Истощение макрофагов уменьшает колонизацию БС раковыми клетками [18]. В экспериментах на мышах было показано, что за метастатическое распространение клеток РЯ отвечают в основном $\mathrm{CD} 163^{+} \mathrm{Tim}^{+}$peзидентные сальниковые макрофаги [19]. В моделях ортотопического РЯ выявлено, что приток нейтрофилов в БС является необходимым предварительным этапом метастазирования. Ткань РЯ продуцирует воспалительные факторы (IL-8, MCP-1 (monocyte chemoattractant protein-1), GRO- $\alpha$ и GRO- $\beta$ (growth-regulated oncogene)), стимулирующие нейтрофилы к мобилизации и экструдированию хроматиновых сетей, называемых внеклеточными ловушками нейтрофилов (NET - neutrophil extracellular traps). Строма БС также может содержать факторы, такие как IL-8 и MCP-1, стимулирующие NET. Еще до метастазов у мышей с РЯ и у женщин с ранними стадиями РЯ выявляются NET в большом сальнике. В эксперименте было показано, что формирование метастазов в БС снижается у мышей с дефицитом выработки нейтрофилами пептидиларгинин деиминазы 4 (PAD4), необходимой для формирования NET [20].

Для роста раковых клеток необходимы специфические метаболические изменения в БС. Сравнительный протеомный анализ клеток РЯ с высоким и низким метастатическим потенциалом показал, что метастазирование сопровождается активацией участвующих в метаболизме жирных кислот генов, которые усиливают синтез фосфолипидов с относительно короткими цепями жирных кислот (миристиновая кислота). Одним из ключевых факторов, способных преобразовывать липидный профиль раковых клеток для метастазирования, является белок ACSL1 (long-chain-fatty-acid-CoA ligase 1), стимулирующий АМФ-активируемую протеинкиназу и Src-путь посредством миристоилирования, что приводит к усилению окисления бета-жирных кислот [21]. Важнейшими источниками последних являются первичные адипоциты БС, которые способствуют хоумингу, миграции и инвазии клеток РЯ. Данные процессы активируются адипокинами, такими как IL-8. Адипоциты действуют как источники энергии для раковых клеток. По сравнению с первичным РЯ для метастазов в БС специфичны более высокие уровни белка FABP4 (fatty acid-binding protein 4) [22]. Для клеток РЯ характерны высокие уровни CD36-рецепторов жирных кислот на плазматической мембране, которые способствуют экзогенному поглощению молекул, предоставляемых адипоцитами БС. Ингибирование CD36 предотвращает развитие индуцированного жировыми клетками злокачественного фенотипа [23].

В метастазах РЯ в большом сальнике белок р53 совместно с вырабатываемым адипоцитами IL-8 активирует экспрессию FABP4, способствуя адсорбции жирных кислот из адипоцитов для поддержания быстрого 
роста раковых клеток [24]. Для серозного РЯ высокой степени злокачественности характерны мутации гена TP53, которые обнаруживаются в 96 \% случаев данного типа опухоли. Мутации вызывают потерю нормальной функции белка p53 [25], который является не только онкосупрессором, но участвует также в регуляции клеточного метаболизма, влияя таким образом на метастазирование РЯ. Мутантный белок р53 может взаимодействовать со стеринсвязывающими белками (SREBP) и гуанидиноацетат-N-метилтрансферазой (GAMT). Это приводит к усилению экспрессии генов ключевых ферментов, участвующих в биосинтезе жирных кислот и холестерина и в ингибировании окисления жирных кислот. Таким путем мутации гена ТР53 способствуют анаболизму липидов и ускоряют рост и прогрессирование опухоли. Кроме того, повышенное количество тромбоцитов в микроокружении РЯ приводит к усилению синтеза TGF- $\beta$, который действует согласованно с мутантным p53 в отношении стимуляции метастазирования за счет усиления активности семейств Twist и Slug/Snail для эпителиально-мезенхимального перехода клеток [24].

В прогрессировании метастазов РЯ важную роль играет не только состав специфических молекул, но и механические свойства БС, так как более жесткий матрикс обладает большей предрасположенностью к росту и развитию метастазов РК [26]. Неблагоприятный исход у больных РЯ связан со взаимодействием вырабатываемого клетками РЯ интегрина альфа 2 (ITGA2) с коллагеновыми волокнами, обильно представленными в опухоли. ITGA2 запускает адгезию раковых клеток к коллагену и способствует их миграции, мезотелиальному клиренсу и устойчивости к аноикису [27]. Экзосомы, происходящие из клеток РЯ и транспортируемые к мезотелиоцитам брюшины человека, оказались обогащенными гликопротеинами клеточной поверхности CD44. Это способствует инвазии рака путем индукции секреции ММР9 и очищения мезотелиального барьера для усиления инвазии клеток РЯ. При подавлении экспрессии CD44 экзосомы оказывают меньшее влияние на мезотелиоциты [28]. CD44, или хоумингассоциированные CAM (cell adhesion molecules), - это семейство трансмембранных гликопротеинов, включая несколько изоформ (в зависимости от особенностей внеклеточного домена за счет комбинаций 10 вариантов экзонов), экспрессируемых в эпителиальных, эндотелиальных и опухолевых клетках. CD44 используются как рецепторы гиалуроната (гликозаминогликана, ответственного за пролиферацию и подвижность клеток). Кроме того, CD44 регулируют клеточную адгезию при взаимодействии с остеопонином, коллагеном, MМР и селектинами. Доказана выраженная экспрессия CD44 неопластическими клетками, что связано с опухолевой инвазией, миграцией и ангиогенезом [29].

Прометастатические изменения в эндотелии БС, необходимые для ангиогенеза, имеют решающее значение в метастазировании РЯ. При исследовании БС больных с метастазами РЯ высокой степени злокачественности была определена повышенная экспрессия ММР9 и VEGFA как в эндотелии, так и в мезотелии по сравне- нию со здоровым контролем [30]. Обнаружено, что метастатические клетки РЯ в сальнике способны экспрессировать VEGFR3, подобно эндотелиоцитам, стимулируя неоваскуляризацию и прогрессирование опухоли [6]. Получены данные о роли VEGF в развитии РЯ в клинических исследованиях с использованием различных методов. Иммуногистохимический (ИГХ) анализ показал повышенный уровень VEGF и VEGFR при РЯ по сравнению с контролем, а также позитивную ассоциацию с метастазами [31]. При помощи генетических методов также было обнаружено, что профили экспрессии VEGF рецепторов и их лигандов значительно выше при метастазах в БС. В связи с этим определение уровней VEGF имеет прогностическое значение при РЯ [32].

\section{Роль систем адгезии в метастазировании рака яичника в большой сальник}

Взаимодействие клеток РЯ с микроокружением БС играет ключевую роль в метастазировании и прогрессировании болезни. В регуляции данных процессов участвуют системы сигналинга молекул адгезии, влияющих на пролиферацию, миграцию и выживаемость раковых клеток [33]. К основным типам белков клеточной адгезии относятся иммуноглобулины, интегрины, кадгерины, селектины и хоуминговые рецепторы лейкоцитов [34]. Их главная роль состоит в формировании межклеточных контактов. Прикрепление раковых клеток к экстрацеллюлярному матриксу происходит главным образом благодаря интегринам, а к мезотелиальным слоям опосредуется такими молекулами адгезии, как ICAM-1 (intracellular cell adhesion molecule-1) и VCAM-1 (vascular cell adhesion molecule 1) [9]. При инициировании туморогенеза клетки РЯ претерпевают эпителиально-мезенхимальный переход, при котором изменяется экспрессия кадгерина и интегрина с активацией протеолитических путей. С током перитонеальной жидкости сфероиды раковых клеток преодолевают аноикис и прикрепляются преимущественно к БС, где они возвращаются к своему эпителиальному фенотипу. Начальные стадии метастазирования регулируются контролируемым взаимодействием рецепторов адгезии и протеаз, а поздние метастазы характеризуются быстрым ростом опухолевых узелков на покрытых мезотелием поверхностях [3].

Межклеточная адгезия опосредуется кадгеринами через кальций-зависимые гомофильные взаимодействия их внеклеточного домена, который связывается с молекулами адгезии соседних клеток, а внутриклеточный домен (цитоплазматический хвост) образует соединения с цитоскелетом и цитоплазматическими белками, такими как катенины [33]. Наиболее часто в межклеточных контактах участвуют «классические» кадгерины, которые играют роль в метастазировании. К ним относятся Е-кадгерин (эпителиальный), Р-кадгерин (плацентарный), N-кадгерин (нейрональный), VE-кадгерин (сосудистый эндотелиальный) Наиболее изученным является Е-кадгерин, который используется в качестве прогностического маркера опухолевого роста [35] (рис. 1). 


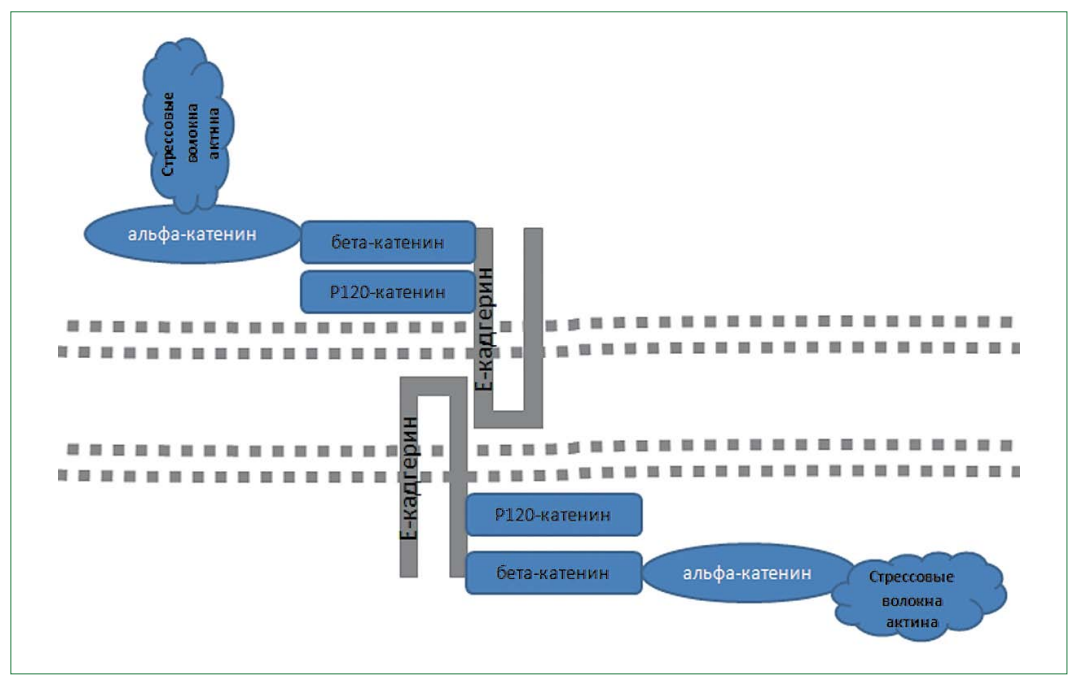

Рисунок 1. Схема участия Е-кадгерина в формировании межклеточных взаимодействий Figure 1. Participation of E-cadherin in the formation of intercellular interactions

В эпителиальных тканях гомофильное Е-кадгериновое лигирование может регулировать локализацию и функцию Rho ГТФазы с помощью механизма «передачи сигналов извне внутрь». Переключение экспрессии с Ена N-кадгерин является важным индикатором прогрессирования рака, так как облегчает эпителиально-мезенхимальный переход, приводящий к образованию раковых клеток с большими миграционной и инвазивной способностями. В метастазирующих солидных опухолях экспрессия Е-кадгерина обычно теряется в связи с онкосупрессорной функцией этой молекулы за счет ингибирующего воздействия на рецептор эпидермального фактора роста (EGFR). Напротив, N-кадгерин, несмотря на сходные структурные и функциональные свойства, ассоциирован с агрессивностью и химиорезистентностью злокачественных новообразований [33]. Е-кадгерин является также объектом воздействия других молекул, участвующих в регуляции опухолевого роста при РЯ. Так, активин-А, уровни которого положительно коррелируют с худшим прогнозом при РЯ, подавляет экспрессию гена Е-кадгерина. Этот эффект устраняется при ингибировании или нокдауне рецептора активина 1-го типа. Кроме того, активин-А стимулирует экспрессию транскрипционных факторов SNAIL и SLUG, которые подавляют синтез Е-кадгерина [36]. Снижение экспрессии гена Е-кадгерина сопровождается ослаблением синтеза интегрина $\alpha 6 \beta 4$, участвующего в формировании гемидесмосом. В результате клетки обретают способность к активной миграции и инвазии. Потеря плотных межклеточных и клеточно-базальных мембранных соединений, опосредованных Е-кадгерином и интегрином $\alpha 6 \beta 4$, приводит к возникновению $\mathrm{N}$-кадгеринзависимых соединений, обусловленных $\beta 1$ и $\beta 3$ интегринами. Такие изменения наделяют клетку повышенным тропизмом к коллагену соединительной ткани. Также $\mathrm{N}$-кадгерин усиливает передачу сигналов факторов роста фибробластов и модулирует сигнальный путь Wnt, что индуцирует метастазирование [37].
Семейство интегринов представлено рецепторами, образованными двумя трансмембранными гликопротеинами, и включает в себя 24 формы гетеродимерных молекул, сформированных комбинациями восемнадцати $\alpha$-субъединиц и восьми $\beta$-субъединиц. При интегринкадгериновых взаимодействиях кадгерины индуцируют злокачественный фенотип и инвазивные свойства раковых клеток, а интегрины регулируют активную миграцию клеток, деградацию экстрацеллюлярного матрикса, интравазацию и экстравазацию. Внеклеточный домен $\beta$-субъединицы интегрина содержит активный центр связывания двухвалентных ионов кальция или магния [37]. Большинство интегринов связывается с актиновым цитоскелетом посредством цитоплазматических линкерных белков, таких как таллин, винкуллин, паксиллин (рис. 2) [34]. Благодаря таким двусторонним связям интегринов обеспечиваются изменения подвижности клеток в ответ на преобразования межклеточной среды. Также интегрины обеспечивают коллективную клеточную адгезию, соединяясь с веществами внеклеточного матрикса и препятствуя дезинтеграции клеточных колоний. Они участвуют в инвазии раковых клеток и передаче онкогенных сигналов на рецепторы факторов роста и определяют локализацию будущих метастазов [37].

Одной из характеристик солидных опухолей является снижение уровня кислорода, которое приводит к накоплению белка HIF-1, инициирующего синтез VEGF. Последний стимулирует экспрессию иммуноглобулин-подобных молекул адгезии (Ig-CAM) ICAM-1, VCAM-1, РECAM-1 в эндотелиоцитах, которые являются поверхностными лигандами для интегринов. Иммуноглобулины, в свою очередь, активируют выработку ММР, которые вызывают деградацию экстрацеллюлярного матрикса, необходимую для начальных этапов метастазирования [38]. Сосудистая сеть в млечных пятнах содержит индикаторы ангиогенеза, к которым относятся CD $105^{+}$сосуды и сосудистые отростки. Мезотелиальные клетки на вершине иммунных агрегатов секретируют VEGF-A. Поэтому метастатические опухолевые клетки преимущественно растут на участках, богатых проангиогенными сосудами, стимулируемыми ангиогенными факторами мезотелиоцитов [7]. К молекулам сосудистой адгезии, способствующим взаимодействию раковых клеток с иммуноцитами при метастазировании рака, относятся L-селектин (синтезируется лейкоцитами), Е-селектин (вырабатывается эндотелиальными клетками) и Р-селектин (продуцируется тромбоцитами и эндотелиоцитами). Их главная функция - привлечение и отбор лейкоцитов в места воспаления или в лимфоидные ткани. Однако они также участвуют в передаче сигналов внутриклеточных и внеклеточных систем и способствуют метастазированию путем рекрутирования миелоидных клеток [39]. Р-селектин опосредует адгезию тромбоцитов и опухолевых клеток, L-селектин облегчает привлечение клеток, происходящих из миелоидных клеток, и вместе с Е-селектином способствует эффективной экстравазации злокачественных клеток. В качестве медиаторов 
соединения селектинам требуются специфические углеводы, такие как Р-селектин-гликопротеиновый лиганд-1 (PSGL-1), сиалированные олигосахариды сиалил-Льюис а $\left(\mathrm{sLe}^{\mathrm{a}}\right)$ и x (sLe $\left.{ }^{\mathrm{x}}\right)$ [29]. На начальных этапах рекрутирования лейкоцитов, L-селектины, синтезируемые Т-лимфоцитами, совместно с Р- и Е-селектинами эндотелиальных клеток, взаимодействуют с эндотелиальными и лейкоцитарными углеводными лигандами. В результате ICAM, CAM1, VCAM-1, совместно с интегринами, усиленно синтезируются для обеспечения прочного прикрепления клеток и передачи внеклеточных сигналов во время трансэндотелиальной миграции. После достижения стабильности межклеточных соединений интегрины $\beta_{1}, \beta_{4}$, ICAM, CAM1, VCAM-1 активируются для дальнейшего усиления первичных связей селектина и передачи сигналов для колонизации здоровой ткани [38]. Метастазирование РЯ инициируется взаимодействиями селектинов с лигандами, после которых происходят взаимосвязи интегринов с экстрацеллюлярным матриксом [40]. При РЯ альтернативно активируемые макрофаги влияют на адгезию раковых клеток к мезотелиоцитам за счет синтеза MIP-1 $\beta$, который активирует передачу в них сигналов CCR5/PI3K. Это приводит к экспрессии Р-селектина на поверхности мезотелиоцитов. В результате раковые клетки присоединяются к этому de novo Р-селектину через CD24, что приводит к усилению их адгезии [41].

\section{Роль большого сальника в защите от прогрессирования рака яичника}

Несмотря на наличие большого количества исследований, свидетельствующих об участии клеток БС в опухолевой прогрессии при РЯ, имеется ряд данных о наличии специфических клеток, ингибирующих канцерогенез в БС. Исследования в данном направлении перспективны как для использования морфологических исследований в прогнозировании исхода у больных с метастазирующим РЯ, так и для разработки таргетной терапии в персонализированной медицине. БС является областью лимфопоэза В1 клеток и иммунного ответа на независимые от Т-клеток антигены. Несмотря на отсутствие фолликулярных дендритных клеток, в БС антигены и клетки из брюшной полости поддерживают зависимые от Т-лимфоцитов В-клеточные ответы, включая переключение изотипа, соматическую гипермутацию и ограниченное созревание аффинности. Кроме того, в БС поддерживается ответ $\mathrm{CD}^{+}$и $\mathrm{CD}^{+}$ Т-лимфоцитов на перитонеальные антигены и рекрутируются эффекторные Т-клетки, праймированные в других областях. В отличие от обычных лимфоидных органов, МП развиваются без клеток-индукторов лимфоидной ткани, но нуждаются в хемокине CXCL13 [42]. С одной стороны, МП большого сальника являются цитотоксическими против раковых клеток, демонстрируя противоопухолевый эффект. С другой стороны, они служат высокоэффективным «естественным фильтром» для скрининга раковых стволовых клеток, обеспечивая тем самым микросреду, в которой раковые клетки формируют метастатические очаги. Этот

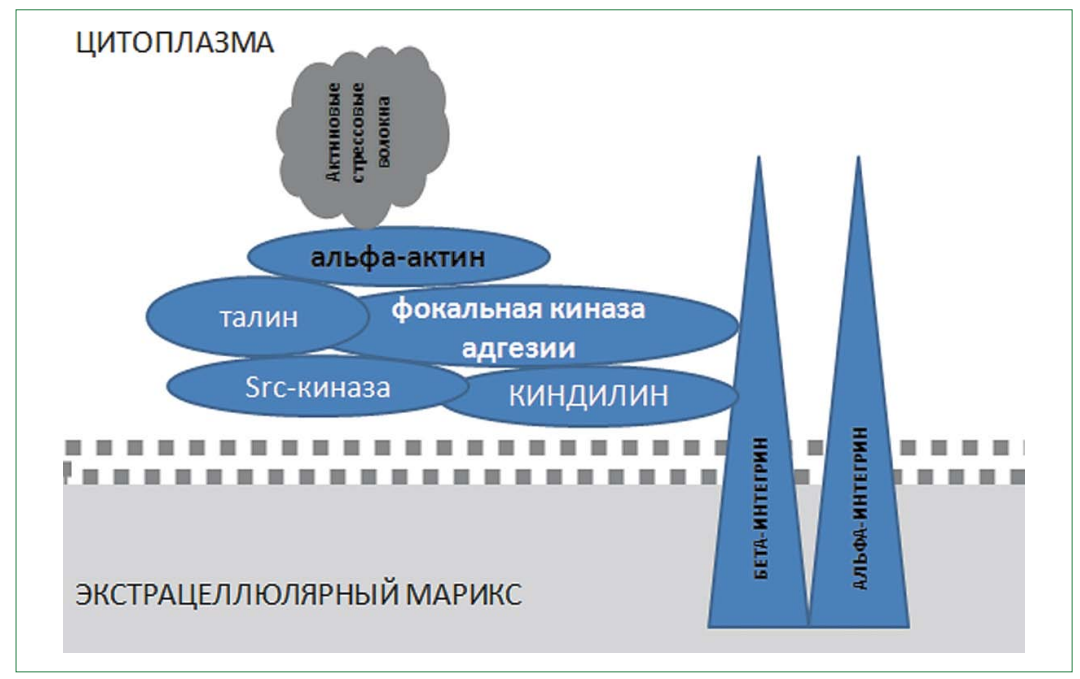

Рисунок 2. Схема строения интегринов

Figure 2. Structure of integrins

феномен связан со способностью макрофагов в различных частях опухоли высвобождать факторы роста, хемокины, ферменты, регулирующие рост опухоли, ангиогенез, инвазию и метастазы. Эти макрофаги мигрируют в МП через кровеносные сосуды под влиянием хемоаттрактантов опухолевого происхождения, к которым относятся CF-1/M-CSF (колониестимулирующий фактор), хемокины CC и VEGF. Затем они дифференцируются в опухоль-ассоциированные макрофаги, которые подразделяют на М1 (провоспалительный и противоопухолевый эффекты) и М2 (иммуносупрессия и стимуляция опухолевого ангиогенеза и метастазов) [9]. Во время опухолевой прогрессии макрофаги проявляют значительную степень пластичности в отношении фенотипического переключения с M1 на M2 [43]. Поэтому определение факторов, регулирующих данные превращения фенотипов, могло бы стать основой для разработки новых методов противоопухолевого воздействия.

Первоначально колонизация опухолевых клеток РЯ вызывает увеличение количества и размеров МП, главным образом путем рекрутирования макрофагов из перитонеальной полости. Несмотря на это, раковые клетки продолжают расти, что может быть обусловлено дефектом в иммунном распознавании или иммуносупрессивным эффектом [8]. Однако наличие Т-клеток внутри РЯ коррелирует с лучшим клиническим исходом при запущенных РЯ [44]. Более того, присутствие $\mathrm{CD}^{+}$Т-лимфоцитов как в первичном РЯ, так и в метастатических опухолях в БС ассоциируется с лучшей выживаемостью пациентов, а отсутствие инфильтрации опухоли Т-клетками приводит к неэффективности лечения РЯ $[45,46] . \mathrm{CD}^{+}$клетки являются цитотоксическими лимфоцитами, которые «убивают» клетки-мишени за счет синтезируемых ими ферментов, таких как гранзим-B. $\mathrm{CD}_{4}^{+}$клетки обычно не являются цитотоксичными, но способны рекрутировать и активировать другие клетки, такие как макрофаги, 
В-лимфоциты, дендритные, воспалительные клетки и другие Т-лимфоциты. Выявлена положительная корреляция инфильтрации опухоли $\mathrm{CD}^{+}$клетками с выживаемостью без прогрессирования и с общей выживаемостью пациентов с РЯ [47]. Генетические исследования показали хороший прогноз у больных с РЯ при экспрессии тканью РЯ хемокиновых лигандов (CXCL10, CXCL11) и рецепторов (CXCR3) для CD8 ${ }^{+}$ Т-лимфоцитов [48]. С худшим прогнозом при РЯ коррелирует накопление $\mathrm{CD}_{3}{ }^{+}$миелоидных супрессорных клеток в БС (под влиянием VEGF), которое ведет к неспособности накапливать $\mathrm{CD}^{+}$клетки [49]. Злокачественные новообразования чувствительны к иммунитету, опосредованному натуральными киллерами (NK) [50]. В экспериментах in vivo на модели ксенотрансплантата мыши показана эффективность высокоактивных NK, полученных из человеческих $\mathrm{CD} 34^{+}$ гемопоэтических стволовых и прогениторных клеток, в инфильтрации и опосредованном уничтожении сфероидов РЯ [51].

\section{Морфофункциональные исследования большого сальника при раке яичника}

Несмотря на наличие большого количества работ по изучению метастазирования РЯ в большой сальник, данная проблема остается актуальной, так как уровень смертности при РЯ сохраняется высоким [1]. Поэтому разрабатываются различные методики исследования БС с целью определения механизмов, лежащих в основе прогрессирования РЯ для возможного таргетного воздействия. Применяют биопсию БС с микроскопией и ИГХ, определение плотности клеток и механических свойств, цитокинов, белков ЭЦМ и профилей РНК. Комплексное применение данных методик показало положительную корреляцию между глобальной клеточной пролиферацией (измеренной с помощью Кi67) и уровнями LTA, IL17A, IL15, CXCL10, а также ассоциацию РЯ с IL12B, IL13, IL16, VEGF, CCLs11, 26, CXCL10 [52]. Важная роль исследований БС заключается в определении прогноза не только у больных РЯ, но даже у здоровых женщин с повышенным риском развития PЯ (например, у носительниц герминативных мутаций в онкосупрессорных генов BRCA1, BRCA2), несмотря на проведение им профилактической сальпинго-оофорэктомии. Это связано с возможным ростом клеток РЯ, находящихся в БС у данных женщин [5]. Поэтому оптимизация морфофункционального анализа большого сальника позволит выявить специфические гистологические маркеры, которые станут основой для молекулярного скрининга риска развития метастатического РЯ у данной категории пациентов.

Но наибольшее значение имеет изучение БС у больных РЯ с имеющимися метастазами. Для исследования функции МП в норме и при канцероматозе используется широкий ряд биофизических и биохимических методов. При световой микроскопии с окраской гематоксилинэозином с увеличением $\times 100, \times 200, \times 400$, млечные пятна визуализируются непрозрачными, круглой или овальной формы, диаметром от 349 до 756 мкм. Их плотность в БС уменьшается с возрастом и составляет от 40-50 на $\mathrm{cm}^{2}$ у новорожденных до $10 \mathrm{~cm}^{2}$ в возрасте старше 70 лет. Диаметр макрофагов неправильной формы в МП составляет 15-20 мкм, Т-лимфоцитов - 7-10 мкм. С помощью сканирующей электронной микроскопии было обнаружено, что макрофаги активированных МП заметно изменяют свою мембранную активность и мигрируют через межклеточные устья мезотелиальных клеток в брюшную полость [9]. Для количественного подсчета МП в большом сальнике используются специальные программы, такие как ImageScope версии 11.1.2.752 (Aperio) [10]. Для исследования клеточного состава МП используется метод жидкостной цитометрии: выделение клеток производят путем измельчения БС в 0,2 \%-ном растворе коллагеназы и вращения в течение 45 минут при $37{ }^{\circ} \mathrm{C}$. Диссоциированные клетки окрашивают анти-CD45 для идентификации гемопоэтических клеток, а также антителами, специфичными для дополнительных маркеров, таких как CD8 и CD4 [6]. Для определения роли жесткости экстрацеллюлярного матрикса БС и его влияния на различные аспекты морфологии и миграции клеток при РЯ применяется метод атомно-силовой микроскопии с измерением значения модуля Юнга. Благодаря этому методу было выявлено, что распространение раковых клеток и формирование очагов адгезии увеличивается на более жестких матрицах. Помимо определения механических характеристик, данный метод позволяет получить изображения биологических образцов с высоким разрешением [26].

Для оценки состояния сосудов при РЯ используют такие маркеры, как CD34 (применяют панэндотелиальные антитела, нацеленные против них). При определении роли плотности микрососудов при РЯ с помощью CD34 было показано повышение показателей выживаемости и выживаемости без прогрессии при высокой плотности микрососудов [53]. У пациентов с РЯ количество циркулирующих CD34 и VEGFR3 ${ }^{+}$ клеток значительно выше, чем у здорового контроля [54]. В связи с ролью Е-кадгерина в подавлении роста РЯ применяются такие методики его определения, как ПЦР в реальном времени, секвенирование нового поколения (NGS) и ИГХ анализ. Последний метод является высокочувствительным и наиболее простым, так как не требует использования дорогостоящего оборудования [55]. Для РЯ высокой степени злокачественности высокоспецифичны мутации гена ТР53, наличие которых является маркером для дифференциальной диагностики с РЯ низкой степени злокачественности. Помимо идентификации мутаций гена ТР53, при изучении РЯ широко применяется ИГХ белка р53. Если необходимо выявить наличие мутантного белка (без идентификации конкретных изменений в последовательности нуклеотидов), чувствительность данного метода составляет 96 \% при сравнении с результатами NGS. Плоскоклеточные карциномы и муцинозный РЯ проявляют феномен терминальной дифференцировки, когда базальные клетки демонстрируют аномальный паттерн ИГХ р53, а апикальные - нет, несмотря на наличие мутации ТР53. Метод ИГХ р53 может быть 
использован для молекулярного тестирования РЯ, так как раковые клетки с мутацией в гене ТР53 не содержат управляющих раком транслокаций [56]. Другим прогностическим биомаркером, ассоциированным с агрессивностью РЯ, является Кi67. Параметры индекса Ki67 могут использоваться для корреляции данных ПЭТ-КТ [57]. Этот белок расположен в ядрах клеток, а его синтез тесно связан с ростом и размножением клеток, поэтому широко применяется в рутинных патологических исследованиях в качестве маркера пролиферации. Ki67 является установленным прогностическим индикатором для оценки биопсий от больных РЯ. Клинически доказано, что Кi67 коррелирует с метастазированием и стадией опухоли, а экспрессия гена этого белка значительно выше в злокачественных тканях с низкодифференцированными клетками [58].

\section{Перспективы исследований большого сальника для терапии рака яичника}

Морфофункциональное изучение БС при РЯ может стать основой для разработки новых путей терапии РЯ. В данном отношении перспективны иммунные стратегии для нацеливания на специфические участки БС и повышения местного противоопухолевого иммунитета, основанные на полученных данных о факторах метастазирования. Так, рост метастазов РЯ в большом сальнике может замедляться за счет стимуляции опухолевого антиген-специфического ответа $\mathrm{CD}^{+}$T-клеток при помощи фагоцитов, нагруженных антигеном липосом, покрытых олигоманнозой [59]. Выявленная роль NET в инициации колонизации клеток РЯ в большом сальнике стала основой для предложения ингибиторов PAD4 (пептидиларгинин деаминаза - фермент, необходимый для формирования NET) для подавления колонизации БС [20]. Мишенью таргетной терапии РЯ может стать FABP4, играющий ключевую роль в метастазировании РЯ в большой сальник [22]. Предполагается использование ингибиторов CD36 для эффективной терапии метастазов РЯ [23]. Перспективным подходом к терапии РЯ является адаптивный перенос аллогенных NK [51]. Большое количество цитостатических NK может быть получено из различных источников, включая пуповинную кровь. Терапия при помощи NK является перспективной стратегией в лечении рака, так как позволяет избирательно воздействовать на раковые клетки без нанесения вреда здоровым тканям [50]. Данные механизмы активно изучаются. Было показано, что активация путей $\mathrm{Wnt} / \beta$ катенина вносит вклад в формирование «холодного» иммунного фенотипа клеток, окружающих опухоли, которые характеризуются слабой эффективностью при терапии блокадой иммунных контрольных точек (ICB). Для лечения данного типа РЯ предложено использование CGX-1321, ингибитора Wnt-путей, который обладает противоопухолевой и иммунностимулирующей активностями, а также значительно снижает опухолевую нагрузку и повышает уровни $\mathrm{CD}^{+} \mathrm{T}$-клеток при РЯ [60]. Одним из перспективных путей терапии метастатического РЯ может стать специфическое ингибирование ITGA2-опосредованных взаимодействий раковых клеток с коллагеном или таргетная терапия фокальных сигналов адгезии [27]. Подавление колонизации БС раковыми клетками возможно также за счет ингибирования CCR1 [5]. Представляет интерес разработка способов воздействия на пластичный механизм переключения фенотипов ассоциированных с РЯ макрофагов из М2 (потенцирует рост метастазов) в М1 (противоопухолевый эффект) [43].

\begin{tabular}{|c|c|c|}
\hline $\begin{array}{l}\text { Название } \\
\text { фактора }\end{array}$ & Характер влияния на метастазы & Источник выработки \\
\hline CCL23 & Стимуляция миграции раковых клеток & Макрофаги БС \\
\hline IL-8 & \multirow{3}{*}{$\begin{array}{c}\text { Стимуляция миграции, инвазии и хоуминга } \\
\text { раковых клеток }\end{array}$} & Адипоциты БС, клетки РЯ \\
\hline MCP-1 & & Клетки РЯ \\
\hline \multicolumn{2}{|l|}{ GRO- $\alpha$ и GRO- $\beta$} & \\
\hline IL-10 & \multirow{2}{*}{$\begin{array}{c}\text { Подавление противоопухолевого иммунного } \\
\text { ответа }\end{array}$} & \multirow{2}{*}{$\begin{array}{l}\mathrm{CD} 4^{+} \mathrm{CD} 25^{\text {high }} \mathrm{CD} 127^{\text {low }} \\
\text { T-супрессоры }\end{array}$} \\
\hline TGF- $\beta 1$ & & \\
\hline FABP4 & \multirow{2}{*}{$\begin{array}{c}\text { Стимуляция поглощения жирных кислот } \\
\text { раковыми клетками }\end{array}$} & Адипоциты БС \\
\hline CD36 & & \multirow{7}{*}{ Клетки РЯ } \\
\hline ITGA2 & $\begin{array}{c}\text { Стимуляция миграции раковых клеток, их } \\
\text { устойчивости и адгезии к коллагену }\end{array}$ & \\
\hline CD44 & $\begin{array}{c}\text { Стимуляция инвазии и адгезии раковых } \\
\text { клеток }\end{array}$ & \\
\hline $\begin{array}{l}\text { Мутантный } \\
\text { белок р53 }\end{array}$ & $\begin{array}{c}\text { Инициация канцерогенеза, стимуляция } \\
\text { трофики раковых клеток за счет регуляции } \\
\text { обмена жирных кислот }\end{array}$ & \\
\hline MMP-2 & \multirow{3}{*}{$\begin{array}{c}\text { Способствуют метастазированию за счет } \\
\text { перестройки матрикса БС, активируют } \\
\text { пролиферацию и ангиогенез }\end{array}$} & \\
\hline TIMP-2 & & \\
\hline MMP-9 & & \\
\hline VEGF, VEGFR3 & Стимуляция неоваскуляризации & \multirow{4}{*}{ Клетки БС } \\
\hline Активин-А & $\begin{array}{c}\text { Стимуляция пролиферации опухолевых } \\
\text { клеток }\end{array}$ & \\
\hline N-кадгерин & $\begin{array}{c}\text { Активация миграции и инвазии раковых } \\
\text { клеток }\end{array}$ & \\
\hline CF-1/M-CSF & Привлечение макрофагов в очаг опухоли & \\
\hline Адипоциты БС & $\begin{array}{c}\text { Активация хоуминга, миграции, инвазии } \\
\text { раковых клеток }\end{array}$ & БС \\
\hline $\mathrm{CD}_{3}+$ клетки & $\begin{array}{c}\text { Стимуляция роста раковых клеток за счет } \\
\text { подавления } \mathrm{CD} 8^{+} \text {Т-лимфоцитов }\end{array}$ & \multirow{5}{*}{ Кроветворные органы } \\
\hline М2-макрофаги & $\begin{array}{c}\text { Иммуносупрессия, стимуляция } \\
\text { метастазирования и опухолевого } \\
\text { ангиогенеза }\end{array}$ & \\
\hline $\begin{array}{l}\mathrm{CD} 4^{+} \mathrm{CD} 25^{\text {high }} \\
\mathrm{CD} 127^{\text {low }} \text { клетки }\end{array}$ & $\begin{array}{c}\text { Подавление противоопухолевого иммунного } \\
\text { ответа }\end{array}$ & \\
\hline М1-макрофаги & $\begin{array}{l}\text { Противовоспалительный и } \\
\text { противоопухолевый эффект }\end{array}$ & \\
\hline CD8 ${ }^{+}$Т-клетки & Противоопухолевый иммунный ответ & \\
\hline Е-кадгерин & Подавление роста опухоли & \multirow{3}{*}{ Клетки РЯ } \\
\hline CXCL10, CXCL11 & \multirow{2}{*}{$\begin{array}{c}\text { Противоопухолевый эффект за счет } \\
\text { стимуляции CD8 }\end{array}$} & \\
\hline CXCR3 & & \\
\hline
\end{tabular}

Таблица 1. Факторы, регулирующие метастазы рака яичника в большой сальник Table 1. Factors regulating metastases of ovarian cancer to the greater omentum 


\section{Заключение}

РЯ является одним из наиболее распространенных злокачественных новообразований женской репродуктивной системы с самой высокой смертностью вследствие бессимптомного течения и диагностики на поздних стадиях. Этим обусловлена низкая эффективность применяемых способов лечения РЯ, несмотря на хирургическое удаление БС, преимущественной области метастазирования данной опухоли. Перспективным направлением в терапии РЯ может стать редактирование противоопухолевых иммунных механизмов. Об этом свидетельствуют данные о лучшей выживаемости женщин с наличием $\mathrm{CD}^{+}$клеток в самом РЯ и метастазах в БС, несмотря на проведенную оментэктомию, так как клетки иммунной системы формируют иммунологическую память для защиты организма от раковых клеток. Поэтому подробное исследование механизмов формирования противоопухолевого ответа при РЯ играет важную роль в разработке стратегий воздействия на данную патологию. Имеющиеся в научной литературе данные многочисленных исследований показали, что важную роль в метастазировании РЯ играют млечные пятна БС. Они отличаются от обычных лимфоидных органов специфическим клеточным составом с преобладанием В1$\operatorname{IgM}^{\mathrm{hi}} \operatorname{IgD}^{\mathrm{lo}}$ лимфоцитов, наличием активных $\mathrm{CD} 4^{+}$и $\mathrm{CD}^{+}$ Т-клеток и отсутствием фолликулярных дендритных клеток. Участие БС в метастазировании РЯ характеризуется свойствами, как способствующими колонизации раковых клеток, так и защищающими от опухолевой инвазии (табл. 1). Активация макрофагов (синтезируют хемокины CCL23) и нейтрофилов в БС, способствующих метастазированию РЯ, связана с воздействием вырабатываемых раковыми клетками рецепторов (CD36) и воспалительных факторов (IL-8, MCP-1, GRO- $\alpha$ и GRO- $\beta$ ). Адипоциты БС служат источниками энергии для раковых клеток, а также потенцируют миграцию, инвазию и хоуминг PK за счет синтеза IL-8, FABP4. В таблице 1 представлены наиболее важные факторы, влияющие на метастазирование РЯ в большой сальник. Они могут быть использованы в качестве мишеней для разработки путей терапевтического воздействия при РЯ. Важную роль в распространении раковых клеток в БС играют молекулы адгезии, многие из которых обладают стимулирующим влиянием на прогрессирование РЯ (ICAM-1, VCAM-1), но некоторые, такие как кадгерин-Е, обладают противоопухолевым действием.

Информация о конфликте интересов.

Конфликт интересов отсутствует.

Информация о спонсорстве.

Данная работа не финансировалась.

\section{Список литературы / References}

1 Stewart C., Ralyea C., Lockwood S. Ovarian cancer: an integrated review. Semin Oncol Nurs. 2019;35(2):151-6. DOI: 10.1016/j. soncn.2019.02.001

2 Yeung T.L., Leung C.S., Yip K.P., Au Yeung C.L., Wong S.T., Mok S.C. Cellular and molecular processes in ovarian cancer metastasis. A Review in the Theme: Cell and Molecular Processes in Cancer Metastasis. Am J Physiol Cell Physiol. 2015;309(7):C444-56. DOI: 10.1152/ajpcell.00188.2015
3 Lengyel E. Ovarian cancer development and metastasis. Am J Pathol. 2010;177(3):1053-64. DOI: 10.2353/ajpath.2010.100105

4 Weidle U.H., Birzele F., Kollmorgen G., Rueger R. Mechanisms and targets involved in dissemination of ovarian cancer. Cancer Genomics Proteomics. 2016;13(6):407-23. DOI: 10.21873/cgp.20004

5 Krishnan V., Clark R., Chekmareva M., Johnson A., George S., Shaw P., et al. In vivo and ex vivo approaches to study ovarian cancer metastatic colonization of milky spot structures in peritoneal adipose. J Vis Exp. 2015;(105):e52721. DOI: 10.3791/52721

6 Sorensen E.W., Gerber S.A., Sedlacek A.L., Rybalko V.Y., Chan W.M., Lord E.M. Omental immune aggregates and tumor metastasis within the peritoneal cavity. Immunol Res. 2009;45(2-3):185-94. DOI: 10.1007/s12026-009-8100-2

7 Gerber S.A., Rybalko V.Y., Bigelow C.E., Lugade A.A., Foster T.H., Frelinger J.G., et al. Preferential attachment of peritoneal tumor metastases to omental immune aggregates and possible role of a unique vascular microenvironment in metastatic survival and growth. Am J Pathol. 2006;169(5):1739-52. DOI: 10.2353/ajpath.2006.051222

8 Meza-Perez S., Randall T.D. Immunological functions of the omentum. Trends Immunol. 2017;38(7):526-36. DOI: 10.1016/j.it.2017.03.002

9 Liu J., Geng X., Li Y. Milky spots: omental functional units and hotbeds for peritoneal cancer metastasis. Tumor Biol. 2016;37:5715-26. DOI: 10.1007/s13277-016-4887-3

10 Clark R., Krishnan V., Schoof M., Rodriguez I., Theriault B., Chekmareva M., et al. Milky spots promote ovarian cancer metastatic colonization of peritoneal adipose in experimental models. Am J Pathol. 2013;183(2):576-91. DOI: 10.1016/j.ajpath.2013.04.023

11 Ben Arie A., McNally L., Kapp D.S., Teng N.N. The omentum and omentectomy in epithelial ovarian cancer: a reappraisal. Part I. Omental function and history of omentectomy. Gynecol Oncol. 2013;131(3):780-3. DOI: 10.1016/j.ygyno.2013.09.014

12 Arie A.B., McNally L., Kapp D.S., Teng N.N. The omentum and omentectomy in epithelial ovarian cancer: a reappraisal. Part II. The role of omentectomy in the staging and treatment of apparent early stage epithelial ovarian cancer. Gynecol Oncol. 2013;131(3):784-90. DOI: 10.1016/j.ygyno.2013.09.013

13 McNally L., Teng N.N., Kapp D.S., Karam A. Does omentectomy in epithelial ovarian cancer affect survival? An analysis of the Surveillance, Epidemiology, and End Results database. Int J Gynecol Cancer. 2015;25(4):607-15. DOI: 10.1097/IGC.0000000000000412

14 Bahar S.G., Rokkam V.R. Omentum Tumors. [Updated 2020 Oct 10] In: StatPearls. Treasure Island (FL): StatPearls Publishing; 2020 Jan-. Available from: https://www.ncbi.nlm.nih.gov/books/NBK563226/

15 Havrlentova L., Faistova H., Mazur M., Ziak D., Polak S. Comparative analysis of human omental milky spots between the patients with colon cancer and the control group. Bratisl Lek Listy. 2017;118(10):580-4. DOI: 10.4149/BLL_2017_111

16 Cipolletta D., Cohen P., Spiegelman B.M., Benoist C., Mathis D. Appearance and disappearance of the mRNA signature characteristic of Treg cells in visceral adipose tissue: age, diet, and PPAR $\gamma$ effects. Proc Natl Acad Sci USA. 2015;112(2):482-7. DOI: 10.1073/pnas.1423486112

$17 \mathrm{Ke}$ X., Shen L. Targeting cytokines secreted by CD $4{ }^{+} \mathrm{CD} 25^{\text {high }} \mathrm{CD} 127^{\text {low }}$ regulatory $\mathrm{T}$ cells inhibits ovarian cancer progression. Scand J Immunol. 2019;89(2):e12736. DOI: 10.1111/sji.12736

18 Krishnan V., Tallapragada S., Schaar B., Kamat K., Chanana A.M., Zhang Y., et al. Omental macrophages secrete chemokine ligands that promote ovarian cancer colonization of the omentum via CCR1. Commun Biol. 2020;3(1):524. DOI: 10.1038/s42003-020-01246-Z

19 Etzerodt A., Moulin M., Doktor T.K., Delfini M., Mossadegh-Keller N., Bajenoff M., et al. Tissue-resident macrophages in omentum promote metastatic spread of ovarian cancer. J Exp Med. 2020;217(4):e20191869. DOI: $10.1084 /$ jem.20191869

20 Lee W., Ko S.Y., Mohamed M.S., Kenny H.A., Lengyel E., Naora H. Neutrophils facilitate ovarian cancer premetastatic niche formation in the omentum. J Exp Med. 2019;216(1):176-94. DOI: 10.1084/ jem. 20181170

21 Zhang Q., Zhou W., Yu S., Ju Y., Kit Yan To S., Sze Tsai Wong A., et al. Metabolic reprogramming of ovarian cancer involves ACSL1-mediated metastasis stimulation through upregulated protein myristoylation. Oncogene. 2021;40:97-111. DOI: 10.1038/s41388-020-01516-4

22 Nieman K.M., Kenny H.A., Penicka C.V., Ladanyi A., Buell-Gutbrod R., Zillhardt M.R., et al. Adipocytes promote ovarian cancer metastasis and provide energy for rapid tumor growth. Nat Med. 2011;17(11):1498-503. DOI: 10.1038/nm.2492

23 Ladanyi A., Mukherjee A., Kenny H.A., Johnson A., Mitra A.K., Sundaresan S., et al. Adipocyte-induced CD36 expression drives ovarian 
cancer progression and metastasis. Oncogene. 2018;37(17):2285-301. DOI: $10.1038 / \mathrm{s} 41388-017-0093-\mathrm{Z}$

24 Hu J., Liu Z., Wang X. Does TP53 mutation promote ovarian cancer metastasis to omentum by regulating lipid metabolism. Med Hypotheses. 2013;81(4):515-20. DOI: 10.1016/j.mehy.2013.06.009

25 Cole A.J., Dwight T., Gill A.J., Dickson K.-A., Zhu Y., Clarkson A., et al. Assessing mutant p53 in primary high-grade serous ovarian cancer using immunohistochamistry and massively parallel sequencing. Sci Rep. 2016;6:26191. DOI: 10.1038/srep26191

26 McKenzie A.J., Hicks S.R., Svec K.V., Naughton H., Edmunds Z.L., Howe A.K. The mechanical microenvironment regulates ovarian cancer cell morphology, migration, and spheroid disaggregation. Sci Rep. 2018;8(1):7228. DOI: $10.1038 / \mathrm{s} 41598-018-25589-0$

27 Huang Y.L., Liang C.Y., Ritz D., Coelho R., Septiadi D., Estermann M., et al. Collagen-rich omentum is a premetastatic niche for integrin a2-mediated peritoneal metastasis. Elife. 2020;9:e59442. DOI: 10.7554/ eLife.59442

28 Nakamura K., Sawada K., Kinose Y., Yoshimura A., Toda A., Nakatsuka E., et al. Exosomes promote ovarian cancer cell invasion through transfer of CD44 to peritoneal mesothelial cells. Mol Cancer Res. 2017;15(1):78-92. DOI: 10.1158/1541-7786.MCR-16-0191

29 Paschos K.A., Canovas D., Bird N.C. The engagement of selectins and their ligands in colorectal cancer liver metastases. J Cell Mol Med. 2010;14(1-2):165-74. DOI: 10.1111/j.1582-4934.2009.00852.x

30 Winiarski B.K., Cope N., Alexander M., Pilling L.C., Warren S., Acheson N., et al. Clinical relevance of increased endothelial and mesothelial expression of proangiogenic proteases and VEGFA in the omentum of patients with metastatic ovarian high-grade serous carcinoma. Transl Oncol. 2014;7(2):267-76.e4. DOI: 10.1016/j.tranon.2014.02.013

31 Wang H., Huang X., Zhang J., Shao N., Chen L.O., Ma D., et al. The expression of VEGF and Dll4/Notch pathway molecules in ovarian cancer. Clin Chim Acta. 2014;436:243-8. DOI: 10.1016/j.cca.2014.06.005

32 Sopo M., Anttila M., Hämäläinen K., Kivelä A., Ylä-Herttuala S., Kosma V.M., et al. Expression profiles of VEGF-A, VEGF-D and VEGFR1 are higher in distant metastases than in matched primary high grade epithelial ovarian cancer. BMC Cancer. 2019;19(1):584. DOI: 10.1186/ s12885-019-5757-3

33 Roggiani F., Mezzanzanica D., Rea K., Tomassetti A. Guidance of signaling activations by cadherins and integrins in epithelial ovarian cancer cells. Int J Mol Sci. 2016;17(9):1387. DOI: 10.3390/ijms17091387

34 Mui K.L., Chen C.S., Assoian R.K. The mechanical regulation of integrin-cadherin crosstalk organizes cells, signaling and forces. J Cell Sci. 2016;129(6):1093-100. DOI: 10.1242/jcs.183699

35 Makrilia N., Kollias A., Manolopoulos L., Syrigos K. Cell adhesion molecules: role and clinical significance in cancer. Cancer Invest. 2009;27(10):1023-37. DOI: 10.3109/07357900902769749

36 Yi Y., Cheng J.C., Klausen C., Leung P.C.K. Activin A promotes ovarian cancer cell migration by suppressing E-cadherin expression. Exp Cell Res. 2019;382(2):111471. DOI: 10.1016/j.yexcr.2019.06.016

37 Janiszewska M., Primi M.C., Izard T. Cell adhesion in cancer: Beyond the migration of single cells. J Biol Chem. 2020;295(8):2495-05. DOI: 10.1074/jbc.REV119.007759

38 Wong C.W., Dye D.E., Coombe D.R. The role of immunoglobulin superfamily cell adhesion molecules in cancer metastasis. Int J Cell Biol. 2012; 2012:340296. DOI: 10.1155/2012/340296

39 Borsig L. Selectins in cancer immunity. Glycobiology. 2018;28(9):64855. DOI: $10.1093 /$ glycob/cwx 105

40 Khaustova N.A., Maltseva D.V., Oliveira-Ferrer L., Stürken C., MildeLangosch K., Makarova J.A., et al. Selectin-independent adhesion during ovarian cancer metastasis. Biochimie. 2017;142:197-206. DOI: 10.1016/j.biochi.2017.09.009

41 Carroll M.J., Fogg K.C., Patel H.A., Krause H.B., Mancha A.S., Patankar M.S., et al. Alternatively-activated macrophages upregulate mesothelial expression of P-selectin to enhance adhesion of ovarian cancer cells. Cancer Res. 2018;78(13):3560-73. DOI: 10.1158/00085472.CAN-17-3341

42 Rangel-Moreno J., Moyron-Quiroz J.E., Carragher D.M., Kusser K., Hartson L., Moquin A., et al. Omental milky spots develop in the absence of lymphoid tissue-inducer cells and support B and T cell responses to peritoneal antigens. Immunity. 2009;30(5):731-43. DOI: 10.1016/j.immuni.2009.03.014

43 Martinez F.O., Gordon S. The M1 and M2 paradigm of macrophage activation: time for reassessment. F1000Prime Rep. 2014;6:13. DOI: 10.12703/P6-13
44 Zhang L, Conejo-Garcia J R, Katsaros D, Gimotty P.A,, Massobrio M., Regnani G., et al. Intratumoral T cells, recurrence, and survival in epithelial ovarian cancer. N Engl J Med. 2003;348(3):203-13. DOI 10.1056/NEJMoa020177

45 Sato E., Olson S.H., Ahn J., Bundy B., Nishikawa H., Qian F., et al. Intraepithelial CD8+ tumor-infiltrating lymphocytes and a high CD8+/ regulatory $\mathrm{T}$ cell ratio are associated with favorable prognosis in ovarian cancer. Proc Natl Acad Sci USA. 2005;102(51):18538-43. DOI: 10.1073/pnas.0509182102

46 Wouters M.C., Komdeur F.L., Workel H.H., Klip H.G., Plat A Kooi N.M., et al. Treatment regimen, surgical outcome, and T-cell differentiation influence prognostic benefit of tumor-infiltrating lymphocytes in high-grade serous ovarian cancer. Clin Cancer Res. 2016;22(3):714-24. DOI: 10.1158/1078-0432.CCR-15-1617

47 Pinto M.P., Balmaceda C., Bravo M.L., Kato S., Villarroel A., Owen G.I., et al. Patient inflammatory status and CD4+/CD8+ intraepithelial tumor lymphocyte infiltration are predictors of outcomes in highgrade serous ovarian cancer. Gynecol Oncol. 2018;151(1):10-7. DOI: 10.1016/j.ygyno.2018.07.025

48 Cancer Genome Atlas Research Network. Integrated genomic analyses of ovarian carcinoma. Nature. 2011;474(7353):609-15. DOI: 10.1038/ nature 10166

49 Horikawa N., Abiko K., Matsumura N., Hamanishi J., Baba T., Yamaguchi K., et al. Expression of vascular endothelial growth factor in ovarian cancer inhibits tumor immunity through the accumulation of myeloid-derived suppressor cells. Clin Cancer Res. 2017;23(2):587-99. DOI: 10.1158/1078-0432.CCR-16-0387

50 Van der Meer J.M.R., Maas R.J.A., Guldevall K., Klarenaar K., de Jonge P.K.J.D., Evert J.S.H., et al. IL-15 superagonist N-803 improve IFN $\gamma$ production and killing of leukemia and ovarian cancer cells by CD $34^{+}$progenitor-derived NK cells. Cancer Immunol Immunother. 2020 Nov 3. DOI: 10.1007/s00262-020-02749-8

51 Hoogstad-van Evert J.S., Cany J., van den Brand D., Oudenampsen M., Brock R., Torensma R., et al. Umbilical cord blood CD $34^{+}$progenitorderived NK cells efficiently kill ovarian cancer spheroids and intraperitoneal tumors in NOD/SCID/IL2Rg ${ }^{\text {null }}$ mice. Oncoimmunology. 2017;6(8):e1320630. DOI: 10.1080/2162402X.2017.1320630

52 Pearce O.M.T., Delaine-Smith R.M., Maniati E., Nichols S., Wang J., Böhm S., et al. Deconstruction of a metastatic tumor microenvironment reveals a common matrix response in human cancers. Cancer Discov. 2018;8(3):304-19. DOI: 10.1158/2159-8290.CD-17-0284

53 He L., Wang Q., Zhao X. Microvessel density as a prognostic factor in ovarian cancer: a systematic review and meta-analysis. Asian Pac Cancer Prev. 2015;16(3):869-74. DOI: 10.7314/apjcp.2015.16.3.869

54 Qiu H., Cao L., Wang D., Xu H., Liang Z. High levels of circulating CD34+/VEGFR3+ lymphatic/vascular endothelial progenitor cells is correlated with lymph node metastasis in patients with epithelial ovarian cancer. J Obstet Gynaecol Res. 2013;39(7):1268-75. DOI: 10.1111/ jog. 12047

55 Rea K., Roggiani F., De Cecco L., Raspagliesi F., Carcangiu M.L., NairMenon J., et al. Simultaneous E-cadherin and PLEKHA7 expression negatively affects E-cadherin/EGFR mediated ovarian cancer cell growth. J Exp Clin Cancer Res. 2018;37(1):146. DOI: 10.1186/s13046018-0796-1

56 Köbel M., Kang E.Y. The many uses of p53 immunohistochemistry in gynecological pathology: proceedings of the ISGyP companion society session at the 2020 USCAP Annual9 Meeting. Int J Gynecol Pathol. 2021;40(1):32-40. DOI: 10.1097/PGP.0000000000000725

57 Mayoral M., Paredes P., Saco A., Fusté P., Perlaza P., Tapias A., et al. Correlation of ${ }^{18} \mathrm{~F}$-FDG uptake on PET/CT with Ki67 immunohistochemistry in pre-treatment epithelial ovarian cancer. Rev Esp Med Nucl Imagen Mol. 2018;37(2):80-6. DOI: 10.1016/j.remn.2017.07.005

58 Li L.T., Jiang G., Chen Q., Zheng J.N. Ki67 is a promising molecular target in the diagnosis of cancer (review). Mol Med Rep. 2015;11(3):1566-72. DOI: 10.3892/mmr.2014.2914

59 Ikehara Y., Shiuchi N., Kabata-Ikehara S., Nakanishi H., Yokoyama N., Takagi H., et al. Effective induction of anti-tumor immune responses with oligomannose-coated liposome targeting to intraperitoneal phagocytic cells. Cancer Lett. 2008;260(1-2):137-45. DOI: 10.1016/j. canlet.2007.10.038

60 Wall J.A., Meza-Perez S., Scalise C.B., Katre A., Londoño A.I., Turbitt W.J., et al. Manipulating the Wnt/ $\beta$-catenin signaling pathway to promote anti-tumor immune infiltration into the TME to sensitize ovarian cancer to ICB therapy. Gynecol Oncol. 2021;160(1):285-94. DOI: 10.1016/j.ygyno.2020.10.031 